\title{
Nova metodologia para análise de conchostráceos em microscópia óptica oriundos de folhelos betuminosos, bacia de Sergipe - Alagoas, Brasil
}

\author{
New methodology to conchostracan analysis in optical microscope from \\ bituminous shale, Sergipe - Alagoas basin, Brazil
}

\section{Nueva metodologia para el analisis de conchostraceos en microscopia optica oriundos de follajes betuminosos, bacia de Sergipe, Alagoas, Brasil}

Novos procedimentos metodológicos para a identificação de conchostráceos foram realizados em amostras de folhelhos betuminosos, oriundas da Bacia de Sergipe-Alagoas (Formação Maceió, Cretáceo Inferior, Brasil), processadas para recuperação de matéria orgânica, nas quais há a presença de uma fauna monoespecifica de conchostráceos (cyzicus pricei) e palinomorfos. A análise das lâminas em microscopia ótica permitiu identificar e reconhecer os fragmentos de conchostráceos, com os padrões de suas respectivas linhas de crescimento, e ornamentações variadas, não perceptíveis em fósseis submetidos à iluminação direta.
New methodological procedures for identifying conchostracans were performed on samples of bituminous shales, derived from the Sergipe-Alagoas Basin (Maceió Formation, Early Cretaceous), processed for recovery of organic matter, where there is the presence of a monospecific fauna of conchostracans (cyzicus pricei) and palynomorphs. The analysis of slides in optical microscopy to identify and recognize the fragments of conchostracans with the standards of their respective lines of growth, and varied ornamentation, no visible fossils submitted to direct light.
Nuevas metodologías para identificar conchostráceos, realizadas en muestras de follajes betuminosos, oriundas de la Bacia de Sergipe, Alagoas, procesadas para recuperar la materia orgánica, en las cuales hay presencia de una fauna mono especifica de conchostráceos (cyzicus pricei) y palinomorfos. El análisis de las láminas en microscopía óptica permitió identificar y reconocer los fragmentos de conchostráceos, con los padrones de sus respectivas líneas de crecimiento, y adornos variados, no perceptibles en fósiles sometidos a iluminación directa.
Palavras-chave: Conchostráceos, Formação Maceió, Sergipe-Alagoas Basin.

\section{Autores:}

Alice F. Souza

Engenharia de Petróleo, Universidade Estácio de Sá, Brasil. Email: alicefsouza@spemail.org

\section{Ismar S. Carvalho}

Departamento de Geologia, Universidade Federal do Rio de Janeiro, Brasil.

Email: ismar@geologia.ufrj.br

\section{introdução}

os conchostráceos são crustáceos que possuem o corpo inteiramente protegido por uma carapaça quitinosa, que geralmente está impregnada por carbonato de cálcio. pelo seu tamanho diminuto, têm sido identificados em testemunhos de sondagem, podendo fornecer informações sobre o fóssil e o ambiente em que se deu a deposição dos sedimentos. essas características tornam os conchostráceos bons indicadores ambientais e a identificação das espécies a partir de fragmentos de carapaça em lâminas amplia sua aplicação paleoambiental e bioestratigráfica.

Seus ovos podem ser submetidos a longos períodos de seca, podendo se dispersar através do vento e da água.
Quando o ambiente volta a ser favorável, os ovos eclodem e o organismo passa por uma fase larvar até chegar à fase adulta. É nessa fase que se forma a carapaça e o organismo começa a viver sobre o substrato dos corpos aquáticos (cArVALHO, 1993).

os conchostráceos, como todos os artrópodes possuem uma cutícula, exoesqueleto, que recobre toda a superfície do corpo e apêndices. esta carapaça está presa ao corpo do or ganismo apenas por um simples músculo, o que faz com que periodicamente ela sofra um acréscimo, enquanto o animal troca todo seu exoesqueleto quitinoso. Possuem zoneamentos de crescimento, separadas por linhas, denominadas como linhas de crescimento, cuja função é ampliar o tamanho da carapaça para acompanhar o crescimento do animal, refletindo, portanto, as fases de desenvolvimento desses crustáceos. As características apresentadas por essas linhas constituem-se no principal foco do estudo da paleobiologia desse grupo de organismos.

Os fósseis oriundos da Bacia de Sergipe-Alagoas (Formação Maceió, Cretáceo Inferior), estão presentes nos níveis de folhelhos betuminosos, onde ocorre uma fauna mono específica (Fig. 1) de conchostráceos (Cyzicus pricei). Todos os exemplares pertencem à mesma espécie, pois apresentam o mesmo padrão de ornamentação microalveolar carenado, característico da espécie Cyzicus pricei. este padrão caracteriza-se por apresentar os minúsculos alvéolos impregnados por carbonato de cálcio. 


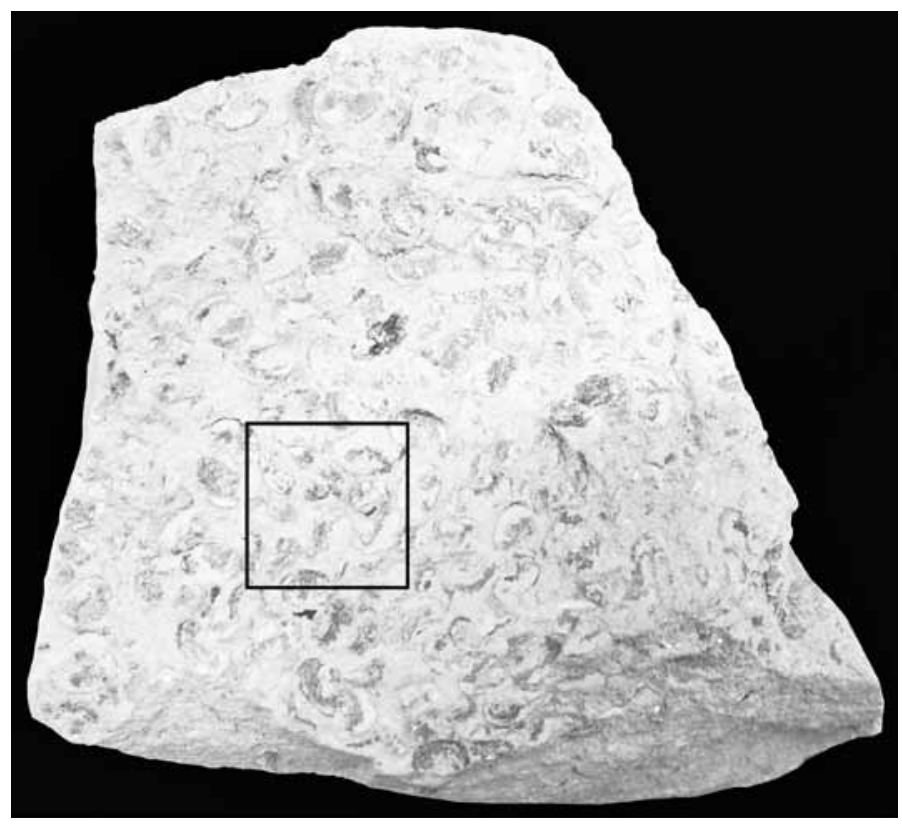

Figura 1 - Nível de mortandade em massa, ocorrência de até 18 espécimes em $2 \mathrm{~cm}^{2}$

Exemplares com diferentes tamanhos indicam que o estágio embrionário de cada ovo em estado de latência era diferente quando ocorreu a eclosão.

\section{Metodologia}

o desenvolvimento de uma metodologia para a recupera ção de fragmentos de conchostráceos possibilita sua identificação através da observação ao microscópio óptico da ornamentação intra-alveolar presente em sua carapaça.

A metodologia foi desenvolvida com amostras de folhelhos betuminosos, oriundos da praia de japaratinga (japaratin ga, Alagoas) da formação maceió, bacia de Sergipe-Alagoas, brasil, através de processamento para recuperação de matéria orgânica seguindo a metodologia de olIveIrA et al . (2006).

foram preparadas lâminas, tomando como base o processamento de amostras para análise palinológica. o material sofreu uma sequência de ataques químicos a fim de se obter um resíduo isento de material inorgânico e húmico, contendo apenas material orgânico com a presença de conchostráceos. o processo consiste das seguintes etapas:

a) coloca-se $40 \mathrm{~g}$ de sedimento em um béquer de vidro de $250 \mathrm{ml}$ e logo em seguida inicia-se a acidificação com ácido clorídrico concentrado $(\mathrm{HCl})$ a $32 \%$ para se eliminar o carbonato.

b) Deixa-se em repouso por $2 \mathrm{~h}$. Após esse tempo, acrescenta-se água destilada para iniciar o processo de neutralização e espera-se o material decantar. com uma peneira de malha de poliéster, peneira-se a solução ácida, e retorna-se o material retido na mesma para o béquer. faz-se esse procedimento até que a água esteja neutralizada.

c) o mesmo procedimento é realizado com o ácido fluorídrico concentrado (HF) a 40\%, visando à eliminação de silicatos. Neste a amostra permanece por $12 \mathrm{~h}$ em repouso. Após a neutralização completa do mesmo, a amostra é acidificada com $\mathrm{HCl}$ a $10 \%$ por $3 \mathrm{~h}$, para a eliminação do fluorsilicato, formado durante o processo anterior e repete-se o procedimento anterior. d) No intuito de eliminar a fração mais grossa do resíduo, e consequentemente proporcionar a concentração dos fragmentos de conchostráceos, faz-se uso de peneira com malha de $200 \mu \mathrm{m}$.

e) Em seguida, o material sofre ataque com ácido nítrico concentrado $\left(\mathrm{HNO}_{3}\right)$ juntamente com clorato de potássio $\left(\mathrm{KClO}_{3}\right)$ com duração de $15 \mathrm{~min}$.

f) Posteriormente é adicionado cloreto de zinco por 20 min, objetivando a separação do material pesado do material mais leve (separação por flotação). Após a separação por flotação, seguida da decantação, adiciona-se ácido $\mathrm{HCl}$ diluído a $10 \%$.

g) O material é então peneirado com malha de $10 \mu \mathrm{m}$, e após a lavagem com água destilada, são preparadas as lâminas usando-se uma chapa aquecedora à temperatura de aproximadamente $30^{\circ}$ e entellan para a colagem da lamínula.

As lâminas preparadas tomam como base o processamento de amostras para análise de palinofácies e fácies orgânica com o intuito de obter amostras com conchostráceos, seguindo como base a metodologia de olIveIrA et al . (2006).

o processo consiste das seguintes etapas:

a) com béqueres de vidro de $250 \mathrm{ml}$, acrescenta-se 40 $\mathrm{g}$ de sedimento e logo em seguida inicia-se a acidificação com ácido clorídrico $(\mathrm{HCl})$ a $37 \%$.

b) Deixa-se em repouso por $18 \mathrm{~h}$. Após esse tempo, acrescenta-se água destilada para iniciar o processo de neutralização e espera-se o material decantar. peneira-se a solução ácida, e retorna-se o material retido na mesma para o béquer. faz-se esse procedimento até que a água esteja neutralizada.

c) $\mathrm{O}$ mesmo procedimento é realizado com o ácido fluorídrico (HF) a 40\%. Neste a amostra permanece por $24 \mathrm{~h}$ em repouso. Após a neutralização completa do mesmo, a amostra é acidificada com $\mathrm{HCl}$ a $10 \%$ por $3 \mathrm{~h}$ e novamente utiliza-se o mesmo procedimento anterior.

d) com o material neutralizado e diluído, passa-se o mesmo para um tubo de ensaio de $250 \mathrm{ml}$, centrifuga-se por $3 \mathrm{~min}$ com velocidade de $1.500 \mathrm{rpm}$. usa-se a peneira para verter o líquido sobrenadante, retornando o material retido na peneira novamente para o tubo de ensaio.

e) Acrescenta-se cloreto de zinco ( $\mathrm{zncl}_{2}$ ) no tubo de ensaio e agita-se. Usa-se a centrífuga por $30 \mathrm{~min}$ ou deixa-se o material em repouso por $12 \mathrm{~h}$ para que a matéria orgânica seja separada do material inorgânico.

f) Com a matéria orgânica separada passa-se para outro tubo de ensaio, acrescenta-se algumas gotas de $\mathrm{HCl}$ a $10 \%$, agita-se bem, coloca-se o tubo na centrífuga por $3 \mathrm{~min}$ a velocidade de $1.500 \mathrm{rpm}$, em seguida verte-se o líquido sobrenadante para a peneira, retornando o material retido novamente para o tubo de ensaio.

\section{Resultados}

A utilização deste método possibilitou a recuperação de fragmentos de carapaças de conchostráceos, de forma indireta através do método de obtenção de palinofácies, fácies orgânicas e palinomorfos.

A análise das lâminas em microscopia óptica permitiu identificar e reconhecer fragmentos de conchostráceos, com suas respectivas linhas de crescimento e ornamentações intra-alveolar (Fig. 2). Os fragmentos de conchostráceos permitiram a observação em luz transmitida de ornamentações variadas, não reconhecidas em fósseis submetidos à iluminação direta (Fig. 3). tal proposição amplia os procedimentos metodológicos para a 


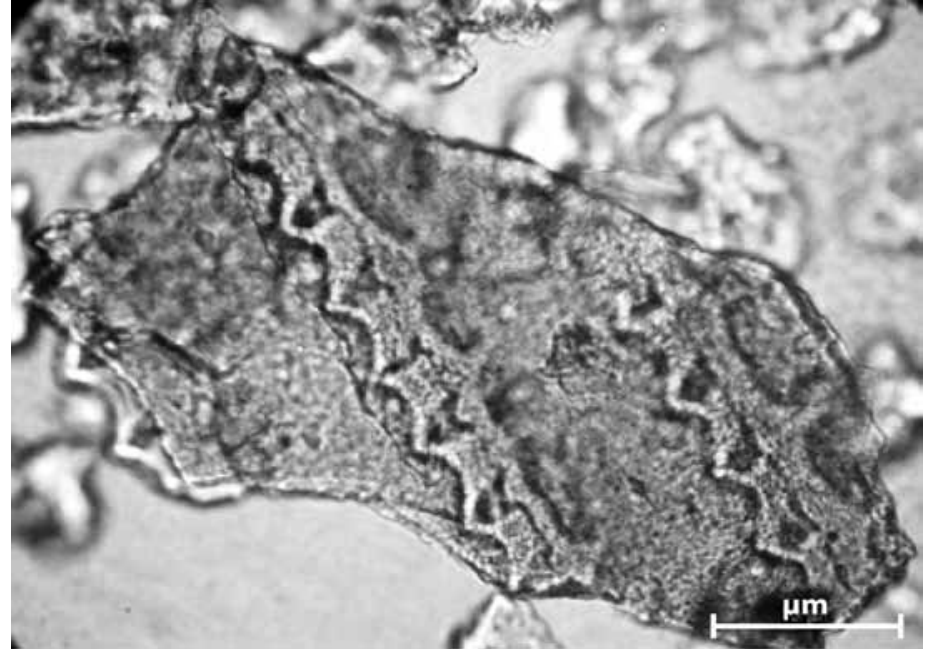

Figura 2 - Ornamentação microalveolar característica da espécie cyzicus pricei
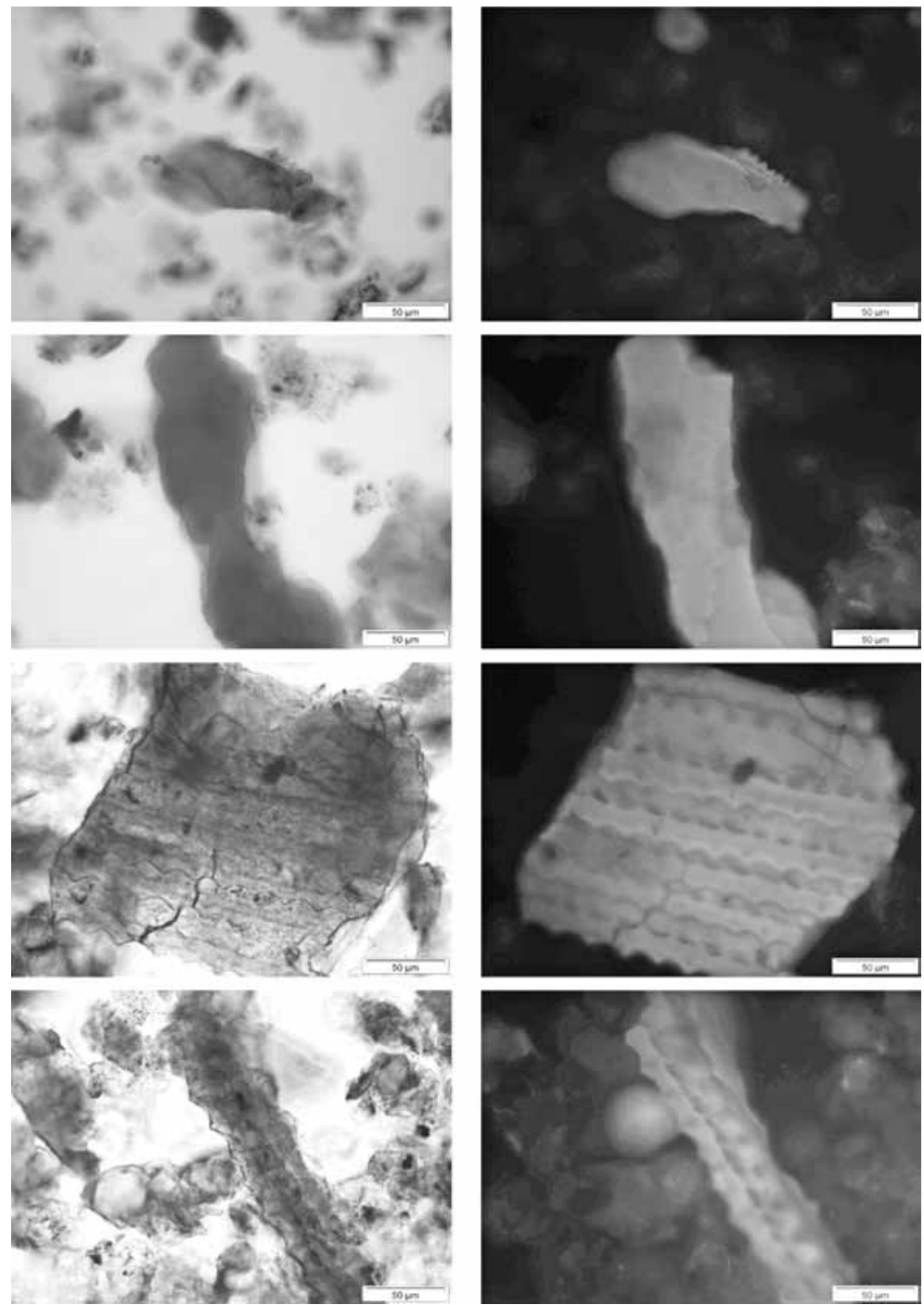

Figura 3 - Fragmentos de carapaça de cyzicus pricei, reparar na ornamentação carenada microalveolar, em luz branca (direita) e fluorescência (esquerda). identificação de conchostráceos possibilitando interpretações paleoambientais e possíveis correlações bioestratigráficas.

\section{Considerações finais}

A recuperação de fragmentos de carapaças de conchostráceos pelo método de obtenção de palinofácies é possível com a preparação de lâminas, tomando como base o processamento de amostras para análise de palinofácies e fácies orgânica.

As lâminas preparadas para obtenção de fragmentos de conchostráceos com preservação de suas linhas de crescimento e ornamentações intra-alveolar, tomando como base o processamento de amostras para análise palinológica mostrou ser eficiente para identificação desses microorganismos e suas estruturas em bom estado de preservação.

\section{Agradecimentos}

À joão graciano medonça filho, por disponibilizar o laboratório de Palinofácies e Fácies Orgânicas (lAfo) para preparação das amostras e a toda sua equipe, em especial, Antônio donizeti de oliveira, joalice de oliveira medonça e jaqueline torres de Souza pela colaboração na preparação e confecção das lâminas e pela análise e fotografia das amostras. Este estudo contou com o apoio da fAperj e cNpq.

\section{Referências Bibliográficas}

CARVALHO, I. S. 1993. Os Conchostráceos Fósseis das Bacias Interiores do Nordeste do Brasil. programa de pósgraduação em geociências, universidade federal do rio de janeiro, tese de doutorado, 310p.

OLIVEIRA, A.D.; MEDONÇA-FILHO, J. G.; SANT'ANNA, A. j.; SouzA, j. t.; freItAS, A. g. \& meNezeS, t. r. 2006. Inovação no processamento químico para isolamento da matéria orgânica sedimentar. In: coNgreSSo brASIleIro de geologIA, 43, Aracaju, 2006. Boletim de Resumos, Aracaju, Sociedade brasileira de geologia, p. 324. 